Open Access

\title{
Focusing in on employability: using content analysis to explore the employability discourse in UK and USA universities
}

Deesha Chadha ${ }^{1^{*}}$ (D) and James Toner ${ }^{2}$

* Correspondence: deesha.chadha@kcl.ac.uk

${ }^{1}$ King's Learning Institute, King's College London, Stamford Street, London SE1 9NH, UK

Full list of author information is available at the end of the article

\begin{abstract}
In this paper, we have taken initial steps towards highlighting the employability discourse in higher education by using content analysis to explore website data at 40 higher education institutions (HEls) in the UK and $40 \mathrm{HEls}$ in the USA by searching for 'employability' in respective web engines. The findings from our preliminary data analysis were inserted into a MIT SIMILE software package to create a bespoke, interactive webpage that could be disseminated for discussion by higher education managers. The initial findings suggest that, in the UK, the broad discourse is centred upon government policies and targeted preparation for employment while in the USA it is centred upon the institutional vision and social inclusion agenda. Recent graduates' views were sought on these initial findings to validate whether their experiences corroborated with our suggested employability discourse claims. These insights are a useful first step for HEls to question and re-evaluate employability at an institutional level.
\end{abstract}

Keywords: Comparative study, Employability, Content analysis, Neoliberal agenda, SIMILE software

\section{Introduction}

In this paper, an attempt is being made to unpack the current discourse around employability in higher education by comparing the situation in the UK with that in the USA so that we can better appreciate the differences and similarities that exist in national settings, their influences and impact, and start exploring practices and policies that can be shared more widely. We were hoping to answer some of the following questions by conducting this research: is the discourse dependent on national or local policies? How large an impact did massification, tuition fees and globalisation have on how HEIs presented their employability discourse? How much could the institution rely on its brand to retain its own independent strategies of securing graduate jobs? The rationale behind this work being carried out is that the current discourse around employability has become increasingly muddled, and yet employability is a key performance indicator when demonstrating institutional success. Time, effort and funding in the form of institutional strategies and resources have gone towards ensuring graduates are employable upon graduation; the measures taken could equally be in vain if we do not have a coherent grasp of the discourse and how it shapes and continues to

(c) The Author(s). 2017 Open Access This article is distributed under the terms of the Creative Commons Attribution 4.0 International License (http://creativecommons.org/licenses/by/4.0/), which permits unrestricted use, distribution, and reproduction in any medium, provided you give appropriate credit to the original author(s) and the source, provide a link to the Creative Commons license, and indicate if changes were made. 
shape employability preparedness in higher education. In the following sections, we have presented a picture of what is currently known of the discourse by attempting to define it and explore its current muddled nature.

\section{Defining employability and its current discourse}

In truth, there are no straightforward definitions of employability. It is perhaps because of this that the ensuing discourse is difficult to determine. Definitions include 'employability being about having the capability to gain initial employment and obtaining new employment if required' (Hillage and Pollard 1998), 'a set of achievements - skills, understandings and personal attributes - that make graduates more likely to gain employment and be successful in their chosen occupations, which benefits themselves, the workforce, the community and the economy' (Yorke 2006) and 'a set of attributes, skills and knowledge that all labour market participants should possess to ensure they have the capability of being effective in the workplace - to the benefit of themselves, their employer and the wider economy' (Confederation of Business Industries (CBI) 2009). More recent definitions include 'that students and graduates can discern, acquire, adapt and continually enhance the skills, understandings and personal attributes that make them more likely to find and create meaningful paid and unpaid work that benefits themselves, the workforce, the community and the economy' (Oliver 2015). These definitions encompass related, but slightly different ideas around the meaning of employability making it difficult to determine upon one solitary definition. As the term employability is a continually changing one given to diverse meaning, this effectively means that there is no overall consensus on what employability means and nor, it seems on what employability discourse represents (Wilton 2011; Frankham 2016). For example, Frankham (2016) suggests that one area of confusion lies in students focusing on outcomes and equating good degree classifications with employment, whereas employers seek capabilities and skills. A second example of perplexity highlighted by Tomlinson (2016) exists in establishing a clear role for the university in preparing graduates when the relationship between student and higher education has become increasingly transactional. For this reason, it may be useful to simultaneously look at employability definitions and discourse and use them to shape a definition that might work for higher education in a national context.

What, then, is known of the employability discourse in higher education? At the beginning of the twenty-first century, a closer functional relationship between higher education and the employment system began to emerge, and so the notion of employability became a key consideration (Knight \& Yorke, 2002; Yorke, 2007; Teichler, 2009). Employability is closely aligned to employment, although acquiring work-related skills does not necessarily result in career-focused employment. For example, the most recent State of the Nation report (2015) suggests the UK is still elitist and that too few entrants from low socio-economic backgrounds access HEIs and jobs; similarly employers are more likely to recruit graduates from elite HEIS (Ibid.). In terms of the resultant outcome of graduate employment, presumptions are made that graduates themselves are academically gifted and employers also harbour expectations that graduates will have developed particular skills and capabilities that make them employmentready when they enter the working environment (for example, Bok 2006). However, graduate jobs are not easy to secure due to competition and a lack of such jobs (Harvey and Bowers-Brown 2004; Rae 2007). Additionally, international markets have opened 
up meaning that graduates are no longer just competing against home-grown talent, but against talented graduates from overseas (Blaxell \& Moore, 2012; Abreu et al. 2014). Every graduate needs to be able to demonstrate that they have an edge over their contemporaries in some way, which is often demonstrated by their enterprise, initiative and mobility (Harvey \& Bowers-Brown, 2004). Graduates are hampered by a reported skills gap or shortage among 'home students' (UK Commission 2014), which has meant that companies are increasingly looking overseas for graduates who have the skills and capabilities that match their requirements. Therefore, higher education institutions (HEIs) are under increasing pressure to do more to support the employability aspirations of their students.

Even though HEIs promote academic excellence, there are still question marks over their ability to support the employability of their students. By and large, HEIs have struggled to make their students more employable and specifically, nurture their employability skills to the standards that satisfy employer expectations (Robst 2007; Hinchliffe \& Jolly, 2011). Gradual changes are being made to redress this balance with groups such as the University Alliance founded in 2006 and made up of British 'anchor institutions' focusing on supporting innovation, skills, lifelong learning and health at a regional level. Students have also expressed concern about their prospects in the employment market. In 2010, for example, an independent survey of 16,114 UK home-based final year students reported that 'just 36\% of those finishing undergraduate degrees this summer [2010] expect to find a graduate job after university and that confidence in the labour market is now at its lowest for fifteen years' (High Fliers 2010). Through a national government debate on the topic, students have called on HEIs to provide clear institution-wide strategies on employability (National Student Forum, 2009).

HEIs are beginning to recognise that there are concerns around catering effectively for the employability of their graduates and have taken up the challenge (Rosenberg et al. 2012). For example, research points towards initiatives that have strengthened the current debate around employability by addressing how higher education educators can better accommodate it (Cranmer 2006). Curriculum intervention, forging better links with employers, establishing more useful modes of assessment, and introducing and developing work-based learning placements are some of the current and known initiatives routinely trialled by HEIs. Their overall effect is somewhat questionable (Ibid.), with the author going on to suggest that a holistic, deep-rooted approach to employability is needed. Additionally, variation and tiers exist within and among HEIs which contribute to the conversation on the outside being as relevant as that on the inside. HEI students increasingly come from a variety of backgrounds which has meant that elite higher education has been replaced by a higher education model serving everyone, but which is still recognised as stratified and hierarchical. What the university does to develop its employability agenda is strongly connected to how it is perceived, what calibre of student it attracts, and what its aspiration entails (Teichler 2015).

\section{Employability, higher education and governance}

In this research, we have elected to compare data from both the UK and the USA. Even though we fully expect the national discourse to be different in both contexts, it would be useful to compare and contrast how content is reflected through context, the rationale for any differences (pull and push factors), and whether good practices can be 
shared. As policy and practice differences are meaningful, it is important to consider how government interventions and recommendations have directed the employability agenda in both the UK and the USA.

In the UK, until the 1980s, higher education policy was largely determined by HEIs themselves. The Haldene principle of government not exerting undue influence over HEIs has given way to what some describe as the neoliberal ideology of those in government (Shore \& Wright 2000; Boden \& Epstein 2006). The situation began changing with the advent of the Thatcher government and the introduction of tighter regulations and controls (Morris 2015). Central government has played a significant role in developing a tighter and a new and different managerialist relationship between themselves, higher education and industry in so far as the employability agenda is concerned. Recommendations from White Papers and government funding schemes have started driving major aspects of the work of higher education in the UK. Examples include the Dearing Report of 1997 which provided a comprehensive review of higher education, and funding schemes, for example Roberts 'SET for success initiative, 2002' aimed at transferable skills development for postgraduates. The Higher Education Academy (HEA), has also taken on an active role, producing an employability framework and accompanying toolkit to embed employability skills in higher education learning. Recent higher education commissions have focused on the collaboration between business and higher education (BIS 2012) and enterprise education (BIS 2013). The fear among higher education practitioners is that self-governance in UK HEIs no longer exists and that Government directs policy and practice (Morris 2015). There is some truth to this argument as more recent government recommendations have supported the introduction of the Teaching Excellence Framework (TEF) which is aimed at improving the quality of teaching by aligning good quality with an increase in the tuition fees HEIs can charge. Employability becomes a performative function of higher education as one of the proposed tools being used to measure institutional success is the Destination of Leavers of Higher Education (DLHE) data, considered a long-standing census. The Government wants data to be readily available to students so that they can make informed choices (Christie 2017), but the danger is that ultimately it is used to make judgements that have far-reaching consequences. More robust insights could be obtained from longitudinal education outcomes (LEO) data, which has recently become available and is based on Her Majesty's Revenue and Customs (HMRC) tax data for all graduates working or claiming benefits in the UK; it effectively records employment activity and inactivity. A secondary consideration of the TEF is the emphasis on social mobility with Jo Johnson (Minister of State for Universities and Science) drawing direct links between teaching quality and the 'outcomes from it.' In other words, social mobility and whether the institution attracts students from low socio-economic backgrounds will become a measure of student success.

The situation in the USA is markedly different, and is based on the Jeffersonian notion of limited and locally-controlled government involvement. Federal government exercises a minimal amount of control over its national universities, both private and public, although increasingly there are calls for Government to exercise greater quality controls, especially as higher education supports the privileged of society (Eckel and King 2004; HE commission 2006; Brint and Clotfelter 2016). Higher education expanded primarily after the Second World War as it was deemed necessary for those 
wanting work to be suitably qualified. Since then, higher education has expanded considerably and it has been suggested that the current challenges it faces are a direct result of its expansion from elite, to mass, to universal education (Trow 2007) (response to the Truman Commission Report of 1947). At its advent, higher education was private, although the Morrill Acts of 1862 and 1890 meant that state governments were able to build and expand public universities. A key issue for policymakers, however, has been the gap that still remains between private and public HEIs and social mobility. Considering the first of these issues, the current state of de-centrality and diversity means that HEIs develop more specific, catered brands that appeal to particular types of students, with higher education being regarded as highly tiered and a multiple segmented sector (Kena et al. 2015). Throughout the 1990s and early 2000s, private colleges tried to become more selective and public colleges add higher-level degrees to stay ahead (Brint et al. 2006). With respect to the social mobility issues being experienced in higher education, it has been argued that it perpetuates the situation by being run on selectivity and on wealth, as mentioned above. Specific minority groups, especially African Americans from low socio-economic backgrounds, usually attend public community colleges and historically black colleges and universities for which completion rates are low. It is also worth bearing in mind that HEIs are beginning to adopt business practices so that institutional systems are efficient (Christensen and Eyring 2011). A concern with this is that it further emphasises the corporate nature of the institution and with resources shifting to fundraising, revenue generation, strengthening ties between local government and the community, the gap between private and public HEIs may widen depending on the saleability of the institutional brand. A combination of the differences in historical background, political ideologies and current governance structures means that we would expect to see differences in the employability discourse in the UK and USA.

\section{Methodological approach}

In this section we explain our methodological approach which consisted of an internet search for 'employability' at a total of 80 HEIs, 40 of which are based in the UK and 40 in the USA. Content analysis was used to analyse this initial data. MIT SIMILE software $^{1}$ was then used to model the data making it simpler to conduct an initial statistical analysis. The internet serves as a useful starting point through which to establish some pointers on what constitutes the employability agenda in higher education and thus was used as our initial research data source (followed by validation from recent graduates). There is a vital impetus on HEIs to champion the products and services they offer and celebrate their successes. Web presence is no indicator of activities related to employment preparation for students, but it provides a useful clue towards identifying what HEIs are doing to promote and acknowledge the employability agenda in accordance with the mission statement or strategic educational objectives of their own institutions. Using the internet, HEIs have advertised their academic credentials effectively and routinely engage with a wider population of people interested in enrolling on distance-learning programmes, for example (Ryan et al. 2000). However, the story is quite different for the less academic, more employability-focused aspects of graduates' all-round education. These successes are little known, at least through the internet, which is the strongest marketing tool at the disposal of any HEI. Therefore, and 
without elaborating on the technologies of the internet, it is perhaps useful to establish the manner in which employability is depicted by HEIs via their web-based presence in consideration of the content of the webpage, its context and the priority it is given.

In answering our research question of establishing the current employability discourse, we have taken a slightly unusual step in that we are principally using the internet as our methodological tool to conduct a content analysis on 'employability' in HEIs. We have done this to surface the hidden discourse - what are HEIs actually doing as opposed to what their institutional vision might comprise? For this reason, we have also sought comments from recent graduates as their experiences draw out the actualities of the discourse around employability at their respective HEIs. In using technology in this way, we are attempting to discover for ourselves how it can be used as a methodological tool, what the actual and more hidden discourse looks like, and to create a platform for sharing. Our findings can therefore be challenged by others who in turn are invited to ask difficult questions of themselves about what they are actually doing to support their students in preparing for employment. To this end, our findings have been shared with institutional managers who were invited to comment on them through a platform created using MIT SIMILE software.

\section{The methodological process}

As this research comprises a comparative study in which we gathered and compared data from UK and USA-based HEIs, we were interested in analysing the data and drawing meaningful inferences in terms of the wider national contexts. The 80 HEIs chosen for this research study were selected by drawing on nationally recognised university rankings tables. The top ten, bottom ten, middle ten, five from the first quarter and five from the third quarter were selected from tables revealing 'best HEIs' rankings for 2013-2014. The UK-based HEIs were selected from the complete universities guide league Table 2013/4, the USA-based HEIs from the US news education colleges: national universities rankings $2013 / 4 .^{2}$ We made the decision to access 80 HEIs so that we could collate the data over the course of one day, meaning that it was comparable within a particular timeframe. We wanted to explore a mix of HEIs from both UK and USA-based contexts. Once the respective website for each HEI had been accessed, the term 'employability' was submitted to the search engine of that HEI.

Even though 'employability' may signify slightly different meanings given the contexts, it proved the best fit for exploring the current discourse around the employability agenda. Other terms were trialled, including 'key and transferable skills' and 'competency-based education', although these terms directed us to too small a number of webpages and were inadequate in providing a holistic, meaningful interpretation of how employability is perceived in higher education. We were conscious of the fact that, had we visited the institutional webpages dedicated to employability of each HEI, our data would reflect the institutional brand and the promotional discourse of the HEIs (Hoang \& Rojas-Lizana 2015). We have made concerted efforts to guard against this, by conducting our own internet search. We are essentially taking on the role of the interested parent of a potential student or the curious industry expert who may 'just google a term to see what comes up.' In the following section, we discuss the process through which we analysed the webpages. 


\section{Conducting content analysis}

The approach we took was that of content analysis. This is influenced by the theoretical and substantive interests of the researcher and the problem being studied (Weber 1990), which in this case was to establish the discourse around employability in higher education and came about from a belief that the discourse was not well established. According to Rourke et al. (2001), content analysis "begins with the compilation of selections of transcripts or entire transcripts into text files. The second step involves creating a protocol for identifying and categorising the target variable(s) and training coders to use this protocol" (p.12). We have been guided by this process in carrying out our research. In terms of the transcripts we selected, the first five sources revealed by the HEI to cite the term 'employability' were accessed and the respective pages printed off. They could then be viewed and analysed in greater depth to formulate an idea of the web-based focus of the institution and where the institutional priority lay. If there were links from the accessed pages to other pages, a note was made of these links. This meant that, in total, 400 webpages were downloaded in this research study. Once we had decided on our target HEIs, transcripts were gathered from our internet search of 'employability' and sorted in institutional order (from top to bottom according to the published rankings). The first five webpages printed off for each HEI were filed. This enabled us to access the data relatively simply for analysing. Copies were made of the webpages and initial notes and impressions written on these copies using checklists based on representation and composition. These notes related to the style of the webpage, colours, fonts and language used and any interesting or unusual aesthetics (representation). A more robust analysis was then carried out in terms of what the content of each individual webpage revealed about employability. As we were focusing our analysis on categories related to employability, our established protocol was to determine what these categories were once we had compiled notes on the initial impressions of the webpages. Berelson (1952) characterises content analysis as primarily descriptive, in which content is described, organised and summarised, and this was the method employed for this research. In terms of creating the description, the webpages were read and analysed twice, by two independent researchers - one started with analysing data from the UK and the other with data from the USA, followed by swapping the data and a discussion to agree and finalise the categories. This was carried out in an attempt to ensure the analysis was as objective as possible and that interpretive bias was limited. All the data was accommodated meaning that some categories might not naturally fit with a working definition of employability, for example 'related to the research ethics procedure of the institution' and 'articles and/or abstracts pointing to academic research on employability and employability related issues' (categories 2 and 11), were also included. This was because we had made a conscious decision that, if we were going to derive a discourse on employability using the internet, every category that emerged would be included. Furthermore, as most content analysis carried out using the internet has no theoretical basis to it, with the focus being on what is measureable rather than on what is theoretically significant (Bryman and Bell 2007), it was important for us to focus on occurrence alongside frequency. Institutional summaries were then jointly compiled by the researchers to include information of the summarised content and the proposed associated narrative of the HEI in relation to employability. Shortened examples are provided as Tables 1 and 2. Table 1 reveals that the first five 
Table 1 Identified categories and summary for Institution A

\begin{tabular}{l}
\hline Institution A (Ivy League HEI, USA) \\
\hline 1 \\
College graduate school magazine article entitled 'report calls for national effort to get missions of \\
A citation from Institution A business school, under faculty and research entitled 'employability \\
security' by Kanter, R.M. (1993) \\
A citation from the Business School of Institution A, under faculty and research entitled 'employment \\
security, employability and sustainable competitive advantage' by Ghoshal, S. et al. (2001) \\
Two-page summary by Nishant Saxena on the employment prospects of Indians entitled 'are \\
employability skills really coachable?' \\
Abstract of article entitled 'a new approach in measuring graduate employability skills' \\
$5 \quad$ Summary first page is interesting as the focus is on a report published at the institution on preparing \\
Toung Americans for the twenty-first century. The report stems from a project and recommends \\
that the range of high-quality pathways offered to students be broadened and more emphasis \\
placed on career counselling and high-quality career education. The remaining four pages (2 to 5) \\
all focus on academic research journal or conference papers mostly related to the Business School \\
of Institution A. The publications are produced by staff at the institution and important questions \\
are being asked about employability internationally. Page 4 is rather interesting as the author has \\
contributed an opinion piece on the difficulty of coaching employability skills, and it is not clear \\
that they are affiliated to the institution. Collectively, these webpages create an impression that \\
the institution is research orientated and perhaps world leading, and is interested in researching \\
local and global questions around employability, although strategies and initiatives that support \\
graduate employment are not prioritised.
\end{tabular}

pages were all directed to research papers and projects around employability. The summary reflects the collective content and what it may suggest about the HEI.

Table 2 shows that the HEI accommodates a number of different aspects in creating an employability footprint.

Each page overwhelmingly highlighted one category. Once the categories had emerged, each page was then colour-coded using pencils and highlighter pens (as we worked with hard copies). By coding in this way, we could revisit the data for further analysis; the data could be entered into the MIT SIMILE software package with relative ease and the statistical analysis could be carried out quickly. For this research, category

Table 2 Identified categories and summary for Institution B

\begin{tabular}{l}
\hline Institution B (Russell Group HEI, UK) \\
\hline 8 \\
Page 1 - Information regarding the success of graduates from Institution A in the market place \\
according to what employers want. Section entitled 'graduate destinations.' \\
Page 2 - Information to support students in their time at the university entitled 'skills and work \\
experience' - providing links directly students to various things they could do in this regard. \\
Page 3 - Page entitled 'Institution B: anything is possible' highlighting the resources available to the \\
students. Opportunity to hear more from students and tutors. \\
Page 4 - Information from the careers service highlighting what is available to students and how \\
they can be supported to gain skills, knowledge and experience \\
Page 5 - Strategic plan of institution from 2013 to 18 \\
The first page points to a success story, and to the success of the institution which potentially sends \\
a message to current and potential students that the institution is not just a place of academic \\
excellence, but that high levels of employability are secured by graduates. The pages imply that the \\
institution shows a good level of support and actively directs the student to things that are in place \\
via links of tools and guidance that students might engage with to enhance their personal/ \\
professional development. Significantly, the tools are there to support students throughout their \\
degree programmes and are not billed as 'quick-fix' solutions, but long-term, considered preparation \\
which calls on students to take some responsibility for their employment preparation. Page 4 points \\
to a link between the careers service and preparation for employability suggesting that the careers \\
service is taking on a central role in supporting students. The strategic plan points towards the \\
vision and priorities of the institution, although the link to employability and how it is catered for \\
within that strategic plan is not explicitly clear.
\end{tabular}


is defined as an aspect of employability which has been revealed from our analysis of the raw data. To give an example of our categorisation process, one page had a feature entitled 'CareerLink'. Further reading and discussion meant that the page could be categorised under 'support, advice, guidance available and/or contact details of the careers centre and/or equivalent unit' (category 4). This process was continued until as many categories as it was possible to identify were identified and no new categories emerged. In total, 18 categories were identified from the raw data. The list of categories that emerged from our analysis of data is provided as Table 3.

The initial findings, in the form of categories and webpage and institutional summaries, were then inserted into a custom site developed using the MIT SIMILE open source software package. Literature suggests that SIMILE software packages bring with them opportunities to actively engage with stakeholders and capitalise on different ways of researching and communicating (Voinov et al. 2016). This was a necessary step for what we hoped to achieve in this research as we were keen to disseminate and share our findings, and encourage institutional managers to consider their institutional data and how these compared nationally and internationally.

According to Muetzelfeldt \& Massheder (2003) SIMILE software:

uses a visual modelling interface because we believe that provides the best way for building, analysing and communicating models. But it aims to overcome the deficiencies of existing visual modelling environments by providing far greater expressiveness, including the ability to handle disaggregation, spatial modelling, and dynamically-varying populations of objects. (p.346)

Table 3 Categories to emerge from webpages (represented as a key)

1. related to supporting employability prospects of students/graduates with disabilities or from disadvantaged backgrounds

2. related to the research ethics procedure of the institution

3. tenuously (or explicitly) related to voluntary work experience opportunities to serve the community in some way, for example campus-community relationships

4. support, advice, guidance available and/or contact details of the careers centre and/or equivalent unit

5. possible careers and/or employability skills developed with focus on particular subject areas and disciplines

6. documents that drive the agenda - policies, employability statements, definitions and institutional strategies related to employability

7. awards, courses, schemes and conferences supporting employability enhancement (awards usually related to enterprise and entrepreneurialism)

8. news feature (or equivalent) advertising the employability record of the HEl or other good news story

9. internships, work experience and other opportunities for students to work and learn in a technical field

10. Q \& A and/or student views on employability/careers

11. articles and/or abstracts pointing to academic research on employability and employability related issues

12. some form of collaboration or opportunity for HEls and industry or alumni to come together

13. mixture of resources directly available to students that support them in developing their employability related skills and capabilities

14. global employability/employing international students

15. cross-cultural learning (for example USA-India business collaborations)

16. advertising of graduate qualifications or related to graduate qualifications (PhDs, masters)

17. technology for employability (skills training, using social media)

18. personal profiles/employment related (for example tribunals) 
Even though the content analysis on the webpages was carried out manually use of the software tool allowed us to visualise the data in a more meaningful way through the model, enabling comparatives to be drawn and a fuller appreciation to emerge of the current situation in UK and USA HEIs. By making use of MIT SIMILE software in this novel way, it was possible to conduct some simple statistical analysis of the data sets and view the data comparatively (regional, cross-national, by ranking, by category) which additionally allowed us to gain further useful insights on the discourse of employability within HEIs and within two national contexts. Figures 1 and 2 are screenshots taken from the SIMILE software, depicting frequency of categories and institutional locations. More detailed information could be accessed by clicking on various links.

Once the initial insights had been revealed from the data, we attempted to validate these findings and subsequently contacted senior managers from each of the 80 HEIs. We invited them to view and comment on the summaries we had generated for their respective HEIs and compare and contrast them with other HEIs both within their national context and internationally through the MIT SIMILE software. This was an important next step as the content analysis points to what can be seen and subsequently inferred internally and externally; however, the data does not tell us how the individuals who constructed the webpages think and behave or how the data ties in with the institutional mission. It was possible to determine the number of individuals who had accessed the MIT SIMILE site and even though this number was over 1000 (Table 4), we did not receive direct comments from any of the senior managers that we had contacted. The approach to data analysis we have taken is summative content analysis as opposed to conventional or directed content analysis (Hsieh and Shannon 2005). This means that we have sought to move beyond counting and categorising towards interpretation. We have generated both quantitative data by exploring categories, determining their frequency and conducting statistical analysis so that we can compare and contrast data from different HEIs and different national contexts, and qualitative data by analysing patterns, creating summaries and interpreting the contextual meanings associated with the data (Weber 1990; Hsieh and Shannon 2005).

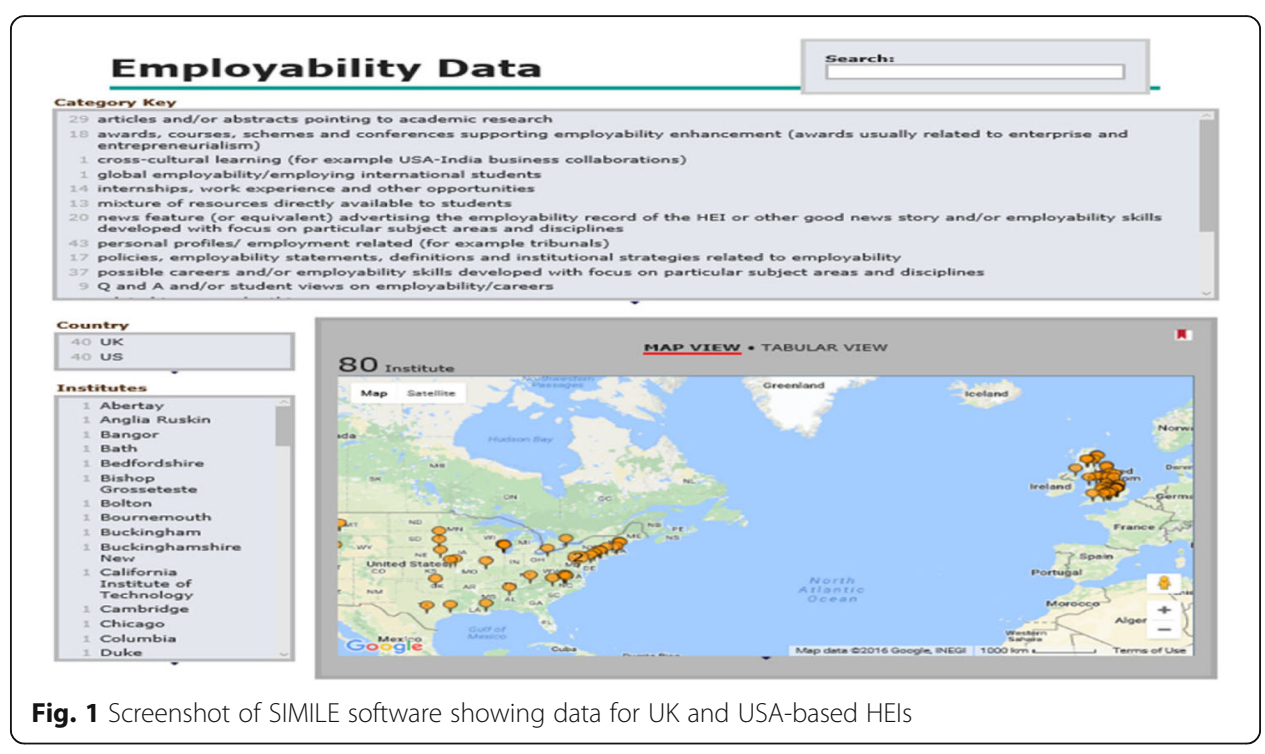




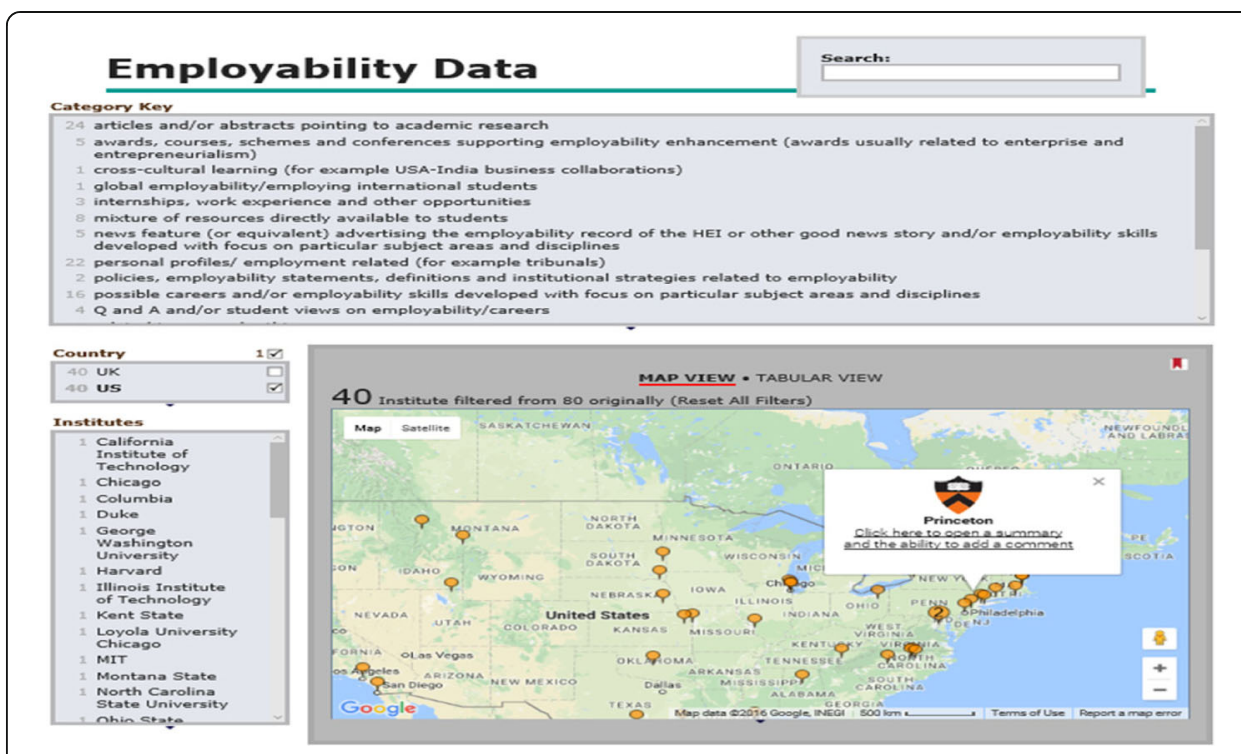

Fig. 2 Screenshot of SIMILE software showing more detailed information of USA-based HEls

\section{Recent graduates' views}

A limitation of content analysis is that it is speculative and cannot be used alone to make definitive claims (Kim and Kuljis 2010), which led to the inclusion of comments from recent graduates in a bid to validate our findings. Ethical approval was obtained to interview recent graduates who had attended HEIs in the UK and USA. They were invited to comment on our initial findings and relate them to their personal experiences of employability in higher education. In total, eight recent graduates took part in this phase of the research, four of whom attended HEIs in the UK and four in the USA. The participants were recruited through word of mouth. Recent graduates known to us were contacted to provide a UK-based perspective and, similarly, family friends in the USA were contacted to recruit recent graduates from the USA. Through snowballing, it was possible to recruit eight participants in total. Interviews were held both face to face and via Skype. In terms of the process employed, in the first instance, the participants were asked to access and browse the custom site that we had developed using the MIT SIMILE open source software package, based on our content analysis of

Table 4 Numbers of views per country of the SIMILE software

\begin{tabular}{ll}
\hline Country & Number of views \\
\hline USA & 371 \\
Not set & 344 \\
UK & 203 \\
Russia & 104 \\
China & 94 \\
Japan & 44 \\
Germany & 28 \\
Netherlands & 24 \\
Spain & 20 \\
South Korea & 20 \\
\hline
\end{tabular}


internet webpages. They were asked to explore the data we obtained through this medium, focusing on what was of interest to them and to also make a note of how they journeyed through the webpage. For example, a few graduates started by searching for their alma mater among the HEIs, while some were interested in comparing the data from their alma mater with other national HEIs, and others began the process by looking to what is being done internationally as opposed to nationally. Participants were essentially encouraged to play with the system, recording open, personal notes of interesting features and their journey through the webpage. They were then provided with some additional findings in the form of statistical data that we generated from the site, and that helped them draw a comparative between UK- and USA-based HEIs (Figs. 3, 4, 5 and 6). In interviewing participants, we asked them to refer to the personal notes they had generated, the statistical analysis we had produced, and encouraged an open conversation in which they were invited to comment on anything they found of comparative interest, jarred with their experiences of employability in higher education or illuminated it.

\section{Findings}

In this section, the results from the statistical analysis which followed on from coding and categorisation are presented. Figure 3 shows how the most frequent nine categories were distributed among the webpages of UK-based HEIs compared with those of USAbased HEIs. The frequency represents each HEI for which the particular category emerged at least once. For example, webpages depicting research papers and projects were downloaded on at least one occasion for 24 of the 40 USA-based HEIs involved in this research.

The data shows there is a relatively high proportion of research articles and conference papers from the USA-based HEIs (24) compared with the UK-based ones (5). HEIs in the USA have produced more research on questions of global importance in

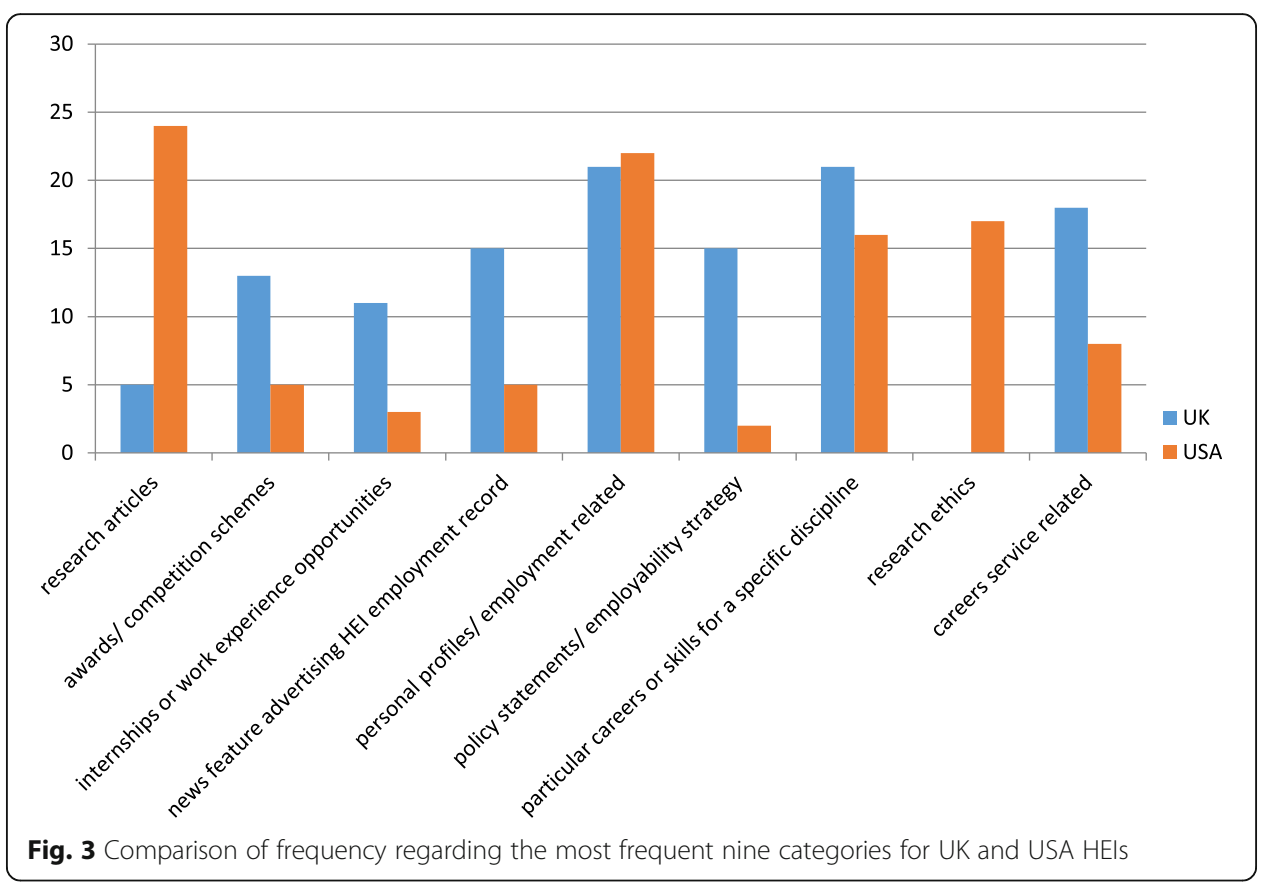




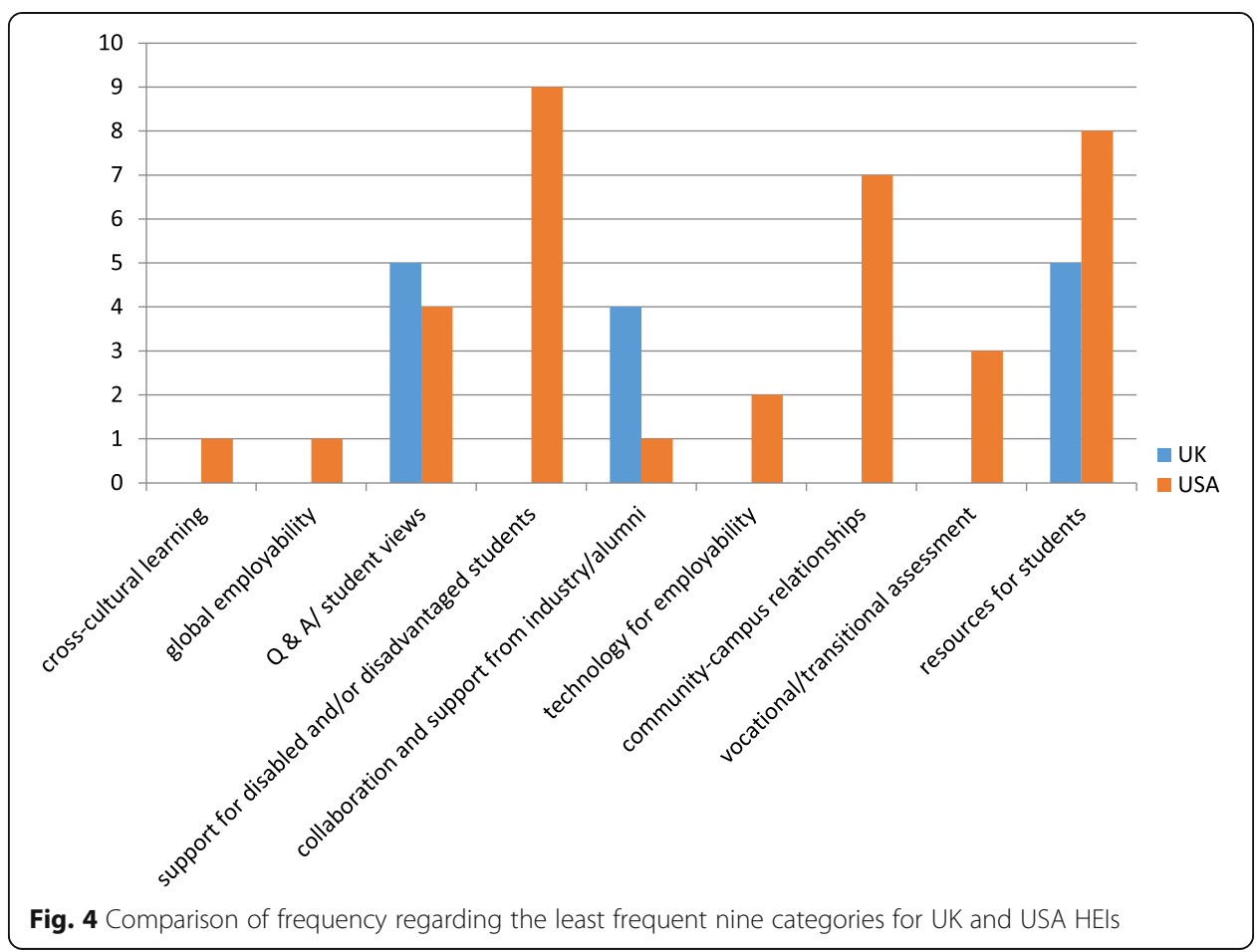

relation to employability, with some of the examples being around questions such as 'tackling low employment in Malawi'. This is followed by research ethics (17 for USA, 0 for UK). Research articles and conference papers do not ordinarily feature as part of the employability agenda, but they do highlight global employability patterns as an area of academic interest. Research ethics, the most anomalous of all our categories to emerge, materialised as a link to questions on USA-based research ethics forms about

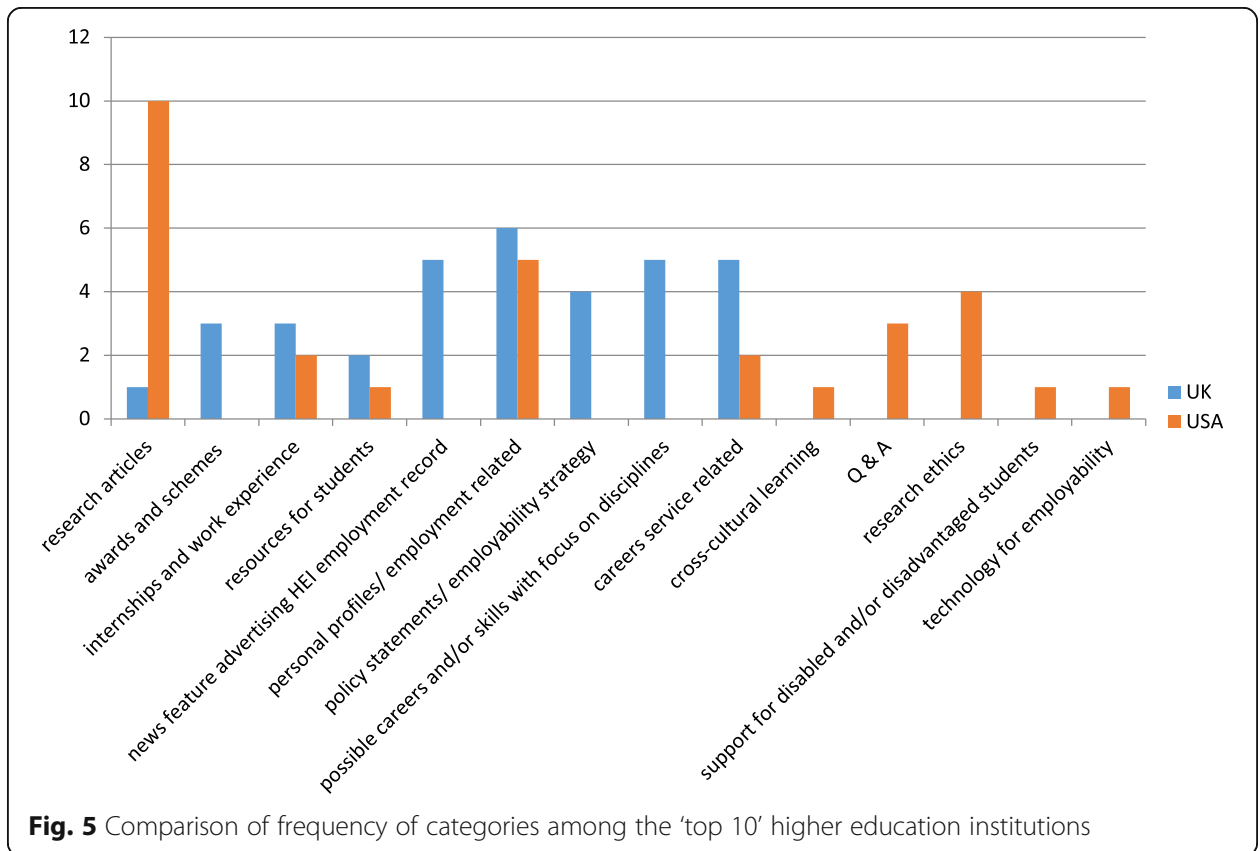




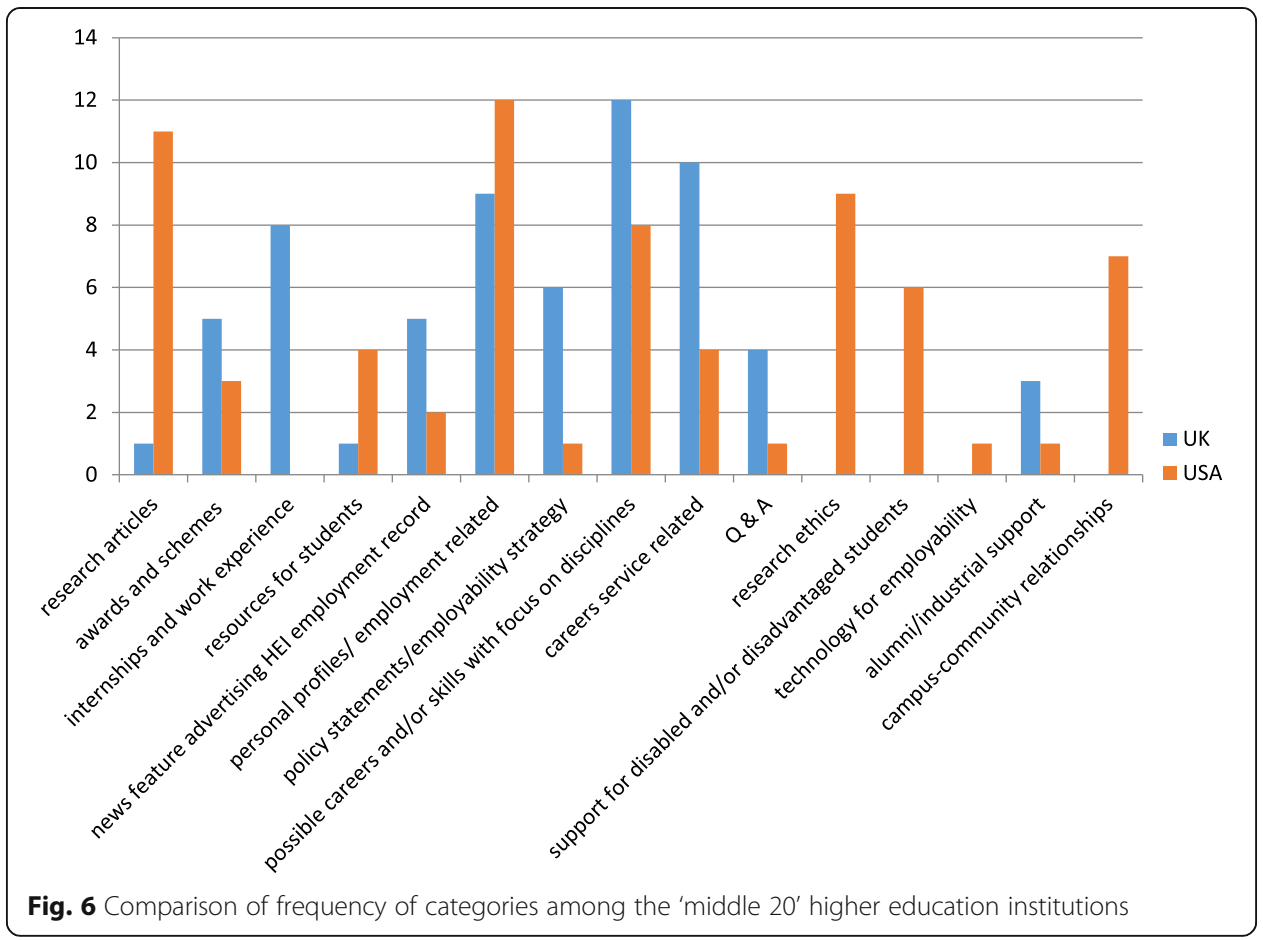

researcher integrity and employment records. In terms of the UK-based HEIs, two of the categories comparatively prevalent are policy statements and employability strategies (15 for UK, 2 for USA) and news features advertising the employment record of the HEIs ( 15 for UK, 5 for USA). Comparatively, the UK also depicts a greater number of pages dedicated to internships and work experience opportunities (11 for UK, 3 for USA), and enterprise award schemes and competitions (13 for UK, 5 for USA). The UK model demonstrates a greater push towards adding to the student experience, and in a way that does not necessarily rely upon changes being made to the academic curriculum. It is interesting to note where the careers service features for both contexts (18 for UK and 8 for the USA). The webpages themselves reveal that, in the UK, the careers service takes greater overall responsibility for graduate preparation than is the case for the USA where careers service units are a lot less prominent.

Figure 4 shows how the least frequent nine categories were distributed among the webpages of UK-based HEIs as compared with those of USA-based HEIs. As with Fig. 3, the frequency represents each HEI for which the particular category emerged at least once.

Of the least frequent nine categories, there are a number that featured highly within the USA based data, but which did not feature at all for the UK-based data, namely support for disabled and/or disadvantaged students (9 for USA) and communitycampus relationships (7 for USA). It is also worth highlighting transitional/vocational assessment as a category, ( 0 for UK, 3 for UK). A couple of the categories featured minimally with only one USA-based HEI acknowledging cross-cultural learning and global employability among the first five pages to be downloaded. Interestingly, these categories did not feature among UK-based data.

Figures 5, 6 and 7 show how all the webpage categories compare for all the HEIs (both UK and USA) that feature in the 'top 10' (Fig. 5), 'middle 20' (Fig. 6) and 'bottom 


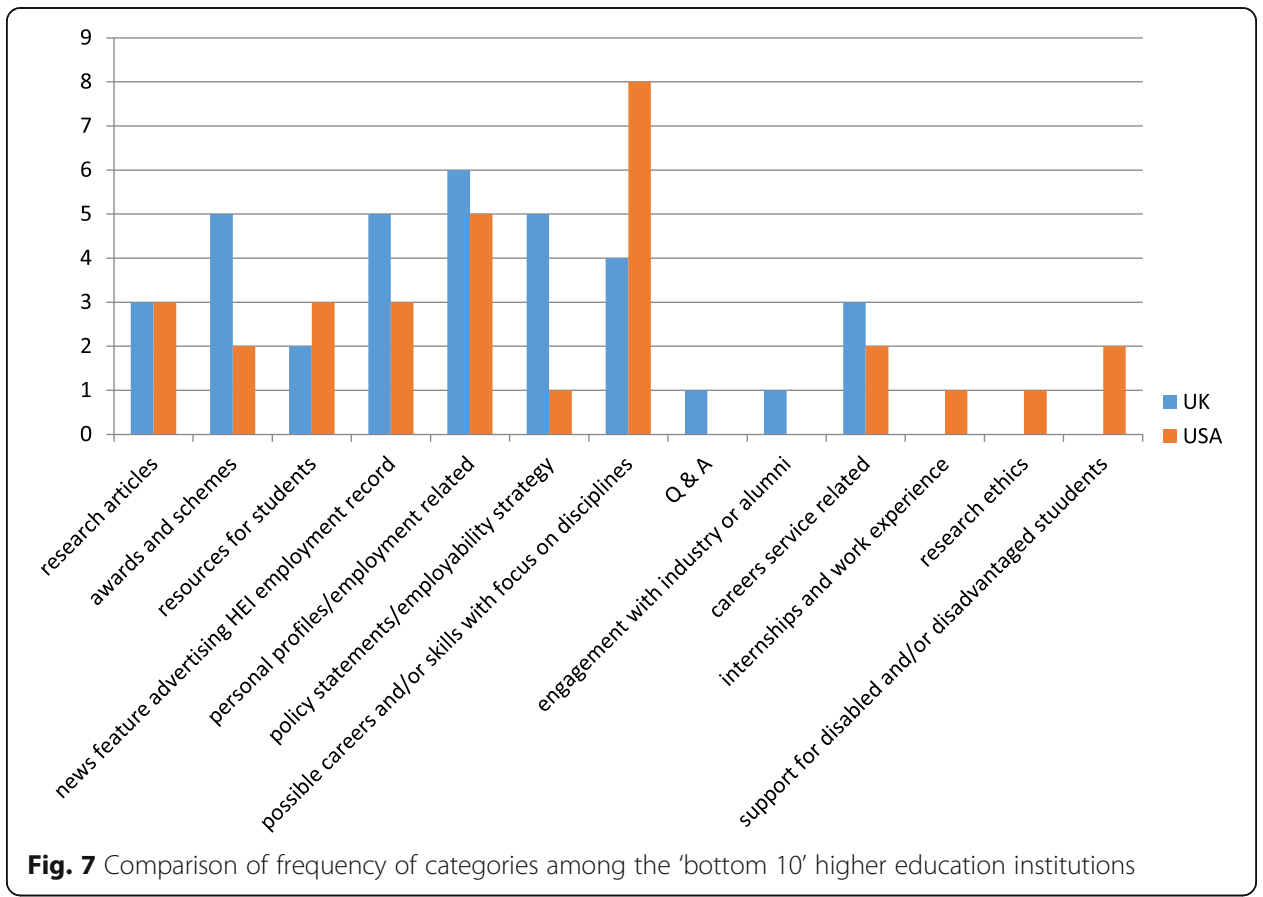

10' (Fig. 7). All the figures reveal that even though there are a number of categories appearing in both UK and USA data, there are also a number only appearing for one national context. For example, among the top ten HEIs, cross-cultural learning, Q \& A, research ethics, disabilities and/or disadvantaged backgrounds, and technology for employability only feature within USA-based data, while awards and schemes, news feature advertising HEI, policy statements/employability strategies, and career/skills with focus on discipline only feature within UK-based data.

Figures 8 and 9, respectively, are a representation of some of the data that was collated for Ivy League and Russell group HEIs. They show how frequently all 18

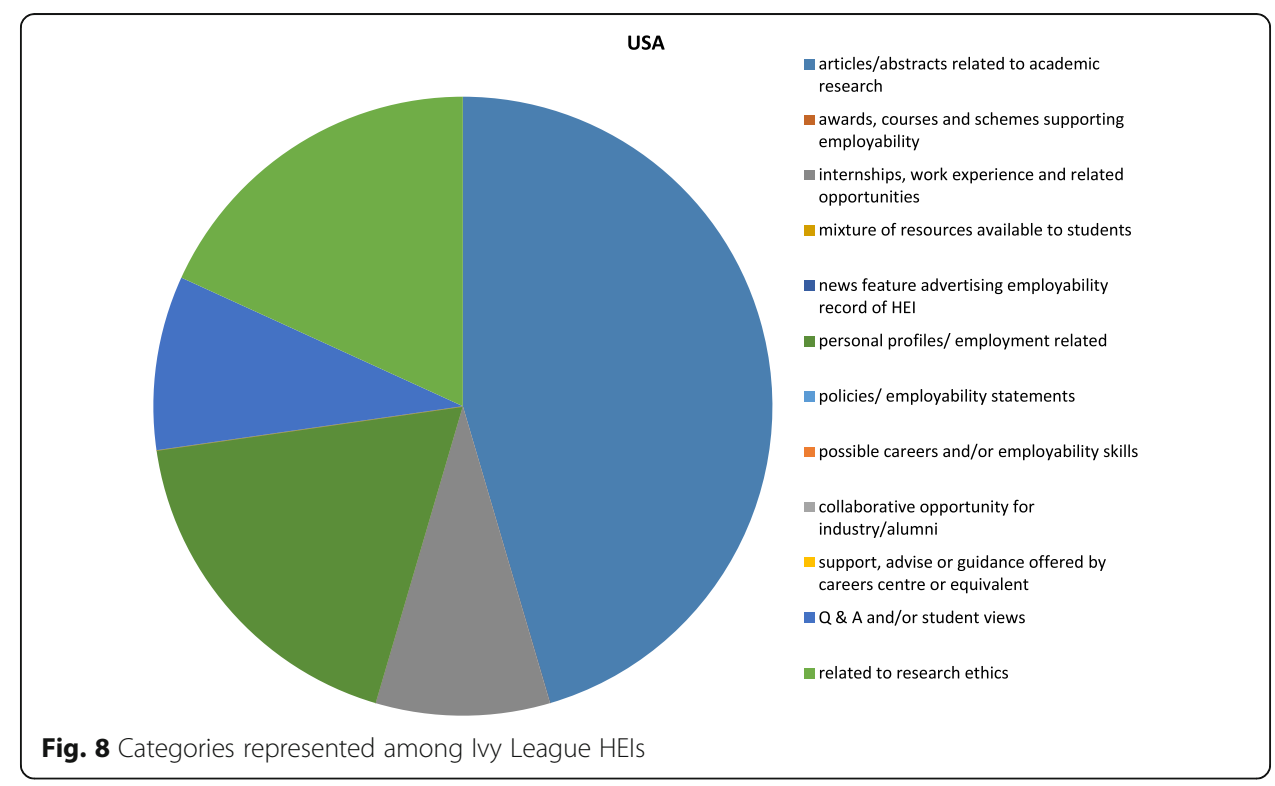




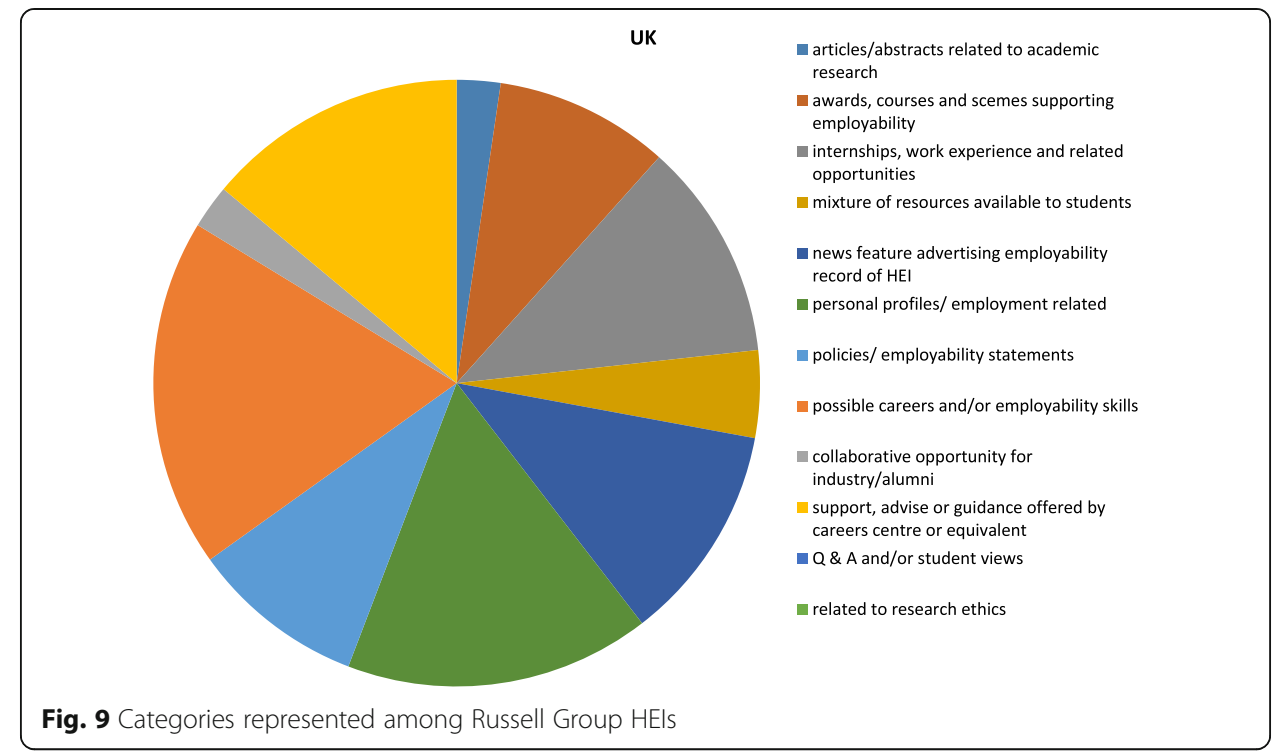

categories were represented in the downloaded webpages of HEIs which we identified as either Ivy League institutions (6) or Russell Group institutions (9) from our selection of 80 HEIs. For the Russell Group HEIs, the categories are fairly mixed, with ten of the 18 categories represented, and this is replicated by the national picture whereas only five categories are represented in Ivy League data. Figure 8 shows that among Ivy League institutions the categories entitled 'articles and abstracts related to academic research' and 'related to research ethics' are relatively sizeable. This may be expected due to the research-intensive nature of these institutions, but equally their inclusion is a surprise as neither category directly or indirectly informs the institutional policy or practices aimed at enhancing employability. Both these categories cannot be ignored as they have genuinely emerged from the research process, but are misnomers.

\section{Discussion}

We have principally based our discussion on our content data analysis and additional comments from recent graduates in the hope that they may collectively reveal something of the international, national and institutional-wide employability discourse in higher education. With respect to the high frequency of UK-based HEIs that cite employability strategies and policy statements (Figs. 3, 5, 6 and 7), we acknowledge that these results are not unexpected due to the recent government recommendations that HEIs produce some form of employability strategy which is made available to their students:

82. Research shows that $69 \%$ of UK institutions have a strategy for enhancing student employability, and calls for all institutions to incorporate an employability strategy into their development process to ensure all students have the opportunity to access a common level of employability skills.

87. Since 2010 HEIs have been required to produce a public statement outlining what they do to promote employability. This statement forms part of the unistats website which hosts the KIS.

BIS (2014) 
Such strategies mean that HEIs can be held accountable by their students and government agendas, pushing responsibility for graduate employability firmly onto the HEIs, with employability very much viewed in this case as a performative function of universities (Boden \& Nedeva 2010; Blackmore \& Sachs 2003; Bylsma 2015). Comparatively little of this is seen in the USA model (Figs. 3, 5, 6 and 7), even though students have been required to pay tuition for their education for a longer period of time. Similarly, news articles may feature more prominently among UK HEIs (Figs. 3 and 5, and to a lesser degree, Figs. 6 and 7) as the recent introduction of tuition fees to the UK has meant that the culture of competition has intensified. A measure of a highly regarded HEI is its ability to secure jobs for its graduates and this is increasingly advertised with headlines such as 'Institution X secures $85 \%$ graduate jobs'. In the UK, there is currently a culture of league table overload as HEIs face increasing pressure to highlight those statistics that show them at their best (Salmi \& Saroyan 2007). Having said as much, ten years ago there were on-going questions around the usefulness of league table results as consumer information and how much such data influenced choices related to what to study and where to study it (Hazelkorn 2007). However, when asked about this, UK-based recent graduates' comments reflected positivity towards the publication of such data and the importance of league tables in helping them make decisions about what and where to study, based on the strength of statistical evidence:

R(UK): They show employability like how many people are likely to get into a job and the success rate of people getting into certain types of jobs. And then like my uni broke it down like to say like with psychology they say like $80 \%$ of people are working 6 months after uni. Then when I actually went and started university they said oh $20 \%$ of those $80 \%$ are actually in psychology related jobs, others are in these types of jobs so it's quite good at showing you.

A(UK): I think that it's good on league tables you can make it course specific so of these certain universities, like the Russell group ones they have specific courses that are good at those unis, but mines not a Russell group uni but my course specifically is really good at that uni and that obviously shows on the league table. When you look at all the event management degrees across the country it's one of the best, but if you look at my uni's position in the whole table it's not as high as it is there so I think that's important.

League tables are representative of a shifting relationship between higher education and students that has become more transactional, founded on consumerist values with practices being increasingly borrowed from the corporate world (Tomlinson 2016). Students want to know what a degree from a particular institution is worth and institutions are keen to point this out. Employability has become an investment project, with the measure of success being about how well an individual can match their human capital profile to the labour market demands, which are increasingly difficult to gauge (Tholen 2015). This also means that a longer-term view is less possible than one that is expectant of immediate results. Graduate employment statistics appear to be less newsworthy in the USA according to participant D. This may be a response to a more institution-based, less policy-orientated approach to employability, and perhaps a different set of expectations among students who perceive that universities just get on with 
the task of creating opportunities that enhance one's employment prospects without drawing attention to themselves.

$\mathrm{D}$ (USA): There was a strong purposeful engagement with industry and from mixers to job conventions... So the statistic given here in this figure on news features that advertise the employment record, I think in the US, I feel that my experience has led me to believe that employability isn't a news worthy event. It is something that is understood by students going into university that there's a course and a team that focus on ensuring that the best opportunities for students of that university will get opportunities ... whether that's mixers and networking events every couple of months or whether it's dropping in for career fairs or interview prep, learning how to get into industry, strategizing and there are specialists in the university who can help you there.

An increase in extra-curricular initiatives in UK-based HEIs may be attributed to the introduction of the higher education achievement report (HEAR). The HEAR called upon students to record their participation in extra- and co-curricular activities, work experiences, voluntary work, enterprise initiatives, positions held within clubs and societies, etc., enabling them to articulate their skills development and capabilities. Figures 3, 5 and 6 show how the categories of internships and work experience and awards and schemes feature highly among UK HEIs. The only anomaly is in Fig. 7 where one HEI from the USA features internships and work experience, but there are no examples from the UK. Enterprise education is especially interesting here as entrepreneurship, as portrayed through internships and award schemes, has become critical in a global economy, and is seen as being at the heart of national economic growth. It is suggested that it is driven by policy and remains a mostly novel approach to graduate development (Henry 2013). The take-up of these activities has proved beneficial and, according to recent research, students and graduates themselves feel that they gain most from work experience opportunities than from any other type of employability strategy (Kinash et al. 2016). Recent research suggests that the international experiences which students engage with while in higher education, for example study abroad schemes, international volunteer work and international internships, better prepare them for the world of work (Crossman \& Clarke 2010). Many HEIs are also developing award schemes to promote extra-curricular employment and life-wide learning (Jackson 2011). Jackson stipulates that, even though these schemes seem to be supporting students, they are usually bolted on to the curriculum rather than being integrated within it, which means that employability is increasingly separate from students' academic development. In the UK there seems to be an increasing push towards identifying explicit activities and opportunities through which students develop their employability; these extra- and co-curricular activities help students further appreciate and articulate their development in this area. Many universities in the UK-based recent graduates:

M(UK): My uni was based in the north so I did a placement year last year so a lot of jobs were available in the north. If you wanted anything in the south you were on your own with that so that's where I'd say it was a disadvantage. But they had a lot of university placements that were paid. I know a lot of people who did those kinds of things because it was convenient to work in the university. 
These opportunities are necessary for students and HEIs alike, as they are reciprocal, with students gaining valuable employability skills while still at university (Higson 2012); according to Helyer \& Lee (2014), 'graduates will need to distinguish themselves by strategically using the experiential learning they gain from in-course workplace experiences if they wish to be considered by graduate recruiters' (p.351). Similarly, having their graduates in graduate jobs boosts the HEIs' profile and potentially increases their numbers of students. We are effectively being called upon to imagine a different notion of curriculum, which perhaps includes social engagement and experiential learning (Millican 2014). According to Speight et al. (2013, p.124), 'there is no need to contest the curriculum if it is understood as a learning space without a beginning or end, and if all learning within higher education is seen as preparation for varied and unknown futures'. A broader description of this learning space encompasses work experience, enterprise education, in-service learning, career management (with support from a careers unit) (Rae 2007), inclusive education and volunteering.

When interviewed, one of the UK-educated recent graduates commented that careers services do indeed take on a substantial responsibility for preparing students to enter the jobs market:

R(UK): Careers related service, I agree with that one again. I think mine was quite good. They helped you even if you were in uni and wanted to send out CVs for things like internships in the summer, summer placements, or to even just sort your $\mathrm{CV}$ out or anything. They were quite good like that.

By and large, the efforts put in by such units are appreciated by recent graduates as is reflected in the UK data especially (Figs. 3, 5, 6, 7 and 9). The current approach taken by careers units is itself more rigorous and sophisticated than the gentle nudging towards filling holes reported on by Brown et al. (2003). Having said as much, a problem with relying on careers services to do this work (if unsupported) is that they are often managed within separate structures, resulting in an intense, but fragmented, approach to employability provision (Rae 2007). Perhaps the nature of responsibility ought to be redefined and instead, if we take engagement as a measure of success rather than employment, then the amount of pressure and expectation currently levelled at careers service units would no doubt reduce (Farenga \& Quinlan 2016). Participant S, from a USA HEI commented on a more integrated approach taken by HEIs in the USA highlighting the interplay between careers, the academic department and the employability centre and that it is the relationship between all three groups that fosters graduate employability:

S(USA): It's very decentralised. There isn't, like there's a careers centre and then there's the team that does employability and then there's also the department itself. And they all have different resources. And so, in many ways most students look at all of them, but only really care about some of them. If I didn't know that I would be surprised because, again the universities that I was part of had a strong presence of trying to get good opportunities for their students. Largely in my opinion because they want that cycle to continue of their ranking and prestige and more students come in.

The suggestion is that employability preparation in the USA is more implicit and subsumed than is the case for the UK. Figures 4, 5, 6 and 7 show two categories where 
the frequency of webpages is greater for the USA than for the UK - support for disabled and/or disadvantaged students and community-campus relationships. Considering the former category, it is important to stress the different type of social model of disability used in the USA as compared with the UK. Harlan Hahn (1988), an American activist and leading authority on disability rights, was influential in creating a model which is socio-political in nature and inclusive, as it simultaneously focuses on the minority-group model. In the USA, inclusivity and equality of access are entwined in accordance with Section 504 - part of the rehabilitation act of 1973, which states that if an educational opportunity is available to any student then it must also be made available to students with disabilities (Aune 1998; Jarrow 1993). A policy framework is already currently in place that needs to be enacted by HEIs and means that, in effect, there is an emphasis on the broader, social context of higher education in the USA that enables students with disabilities and disadvantaged students to feel supported. It is also worth mentioning vocational/transitional assessment here (Fig. 4) as it is closely aligned with disability policies in the USA. This aspect of employability is mostly utilised by secondary schools rather than higher education in the USA and serves as a mechanism to ensure that students, especially those with disabilities, are aware of the opportunities open to them beyond post compulsory education. The Individuals with Disabilities Education Act of 1997 (IDEA) has meant that secondary schools are obliged to engage with transition planning (Condon and Callahan 2008), although the limited number of examples suggest that transition/vocational planning has also started featuring in higher education.

With respect to USA-based community-campus relationships, unpaid internships and volunteer work are heavily weighted by potential employers (The Chronicle, 2012); this may account for the fact that funding was made available in the USA through several federal programmes to fuel this initiative. HEIs in the USA have adopted communitycampus partnerships as a constructive mechanism through which their students are able to develop employability skills and serve their community (Pasque et al. 2005). These partnerships are based on promoting a broad sense of civic responsibility in higher education through in-service learning - often considered a central part of the mission of USA higher education - and are viewed as positive, win-win situations (Bringle \& Hatcher, 2002). One of the participants from the USA commented upon the value of these community-campus relationships:

T(USA): Yeah that's right ... I guess the set up was the same. If anything I would dispute the numbers you've come up with. In the states, or at least in my university it's a really big thing, cos we have campuses, and people are like really keen to get involved, mostly because they want to have something good to put on their resume ... everyone's a winner - you because you did something worthwhile, the community that benefited from you giving your time and the university as it didn't have to do anything much - it's an organic process that makes the university look like it supported the opportunity.

As student $\mathrm{T}$ implies, in-service learning is recognised as a values-based approach that augments employability skills and capabilities developed elsewhere in the curriculum (Kinash et al. 2016). The perspective offered by participant $T$ is contrasted with 
the experience of participant $\mathrm{H}$ who studied at a UK-based HEI, and who was less familiar with community-campus partnerships:

H(UK): It says that there's no campus community relationship in the UK. I would agree with that to a certain extent as I don't feel there's, that we don't have many ties to the community. But at the same time my uni is the centre of and is a massive part of the town itself. So even though I may not see it, I think there are links with the town. I might not necessarily have that much of an insight into it.

In relation to Figs. 8 and 9, the categories mentioned may feature within the strategic frameworks and various mechanisms that support employability, but they were not represented by the first five pages downloaded, meaning that they were given less priority by the institutional intranet and subsequently the internet. A subtle difference can be drawn out here between the Russell Group and Ivy League institutions regarding how these HEIs represent themselves and what they focus on in terms of the employability agenda. This could be attributed to higher education being heavily regulated due to the public funding that is behind student loans, as is the case for the UK compared with self-governing HEIs, and as is the case for the USA mentioned earlier. Additionally, the web pages of Ivy League institutions do not immediately address the direct preparation of their students before they enter the job market. Earlier evidence from the USA indicates that students themselves attach importance to the profile of the HEI they graduate from (Tomlinson, 2008), which may reflect the belief among Ivy League institutions that it is unnecessary to draw attention to their employability statistics - elite HEIs use their institutional reputations to support their graduates in finding good jobs; networks and alumni are vital for these institutions (Brown et al. 2003). Participant AK has also spoken about elite education in the USA and how a different set of values and ambitions drive employability:

AK(USA): Ivy League doesn't go for hard sell, it doesn't need to. The alumnis might have partnerships and people can gain opportunities if I want to go into the arts and sciences. This is where I think most of that information is in the departments... For example when I was applying I found most of that information in the departments. We have so and so. When I was applying I didn't go to careers websites ... I feel looking at this, that there is a disadvantage in the UK, they're not at as competitive a level as the US in terms of the employability. And it also makes sense because sometimes of the pool of students coming into university, that makes a difference as well.

The institutional reputation has leverage among employers; a more recent survey conducted in the USA suggested that employers themselves weight the brand reputation of the HEI when assessing potential employees (The Chronicle 2012). The implication here is that more recent notions around graduate identity (Holmes 2001; Valenzuela 2013) based on the institutional identity, are beginning to replace universal graduate transferable skills and competencies, so that employability preparedness is institutionally rather than disciplinarily aligned. By focusing on specific aspects of employability, the data suggests that more middle-ranked HEIs are also beginning to develop an institutional brand and generate employability capital through their focus 
on employability, mainly by offering work placements, volunteer engagement programmes and directed support through their careers service.

\section{Methodological limitations}

We acknowledge that there are methodological limitations to the research we have carried out. Firstly, there is an issue of validity in using institutional webpages featuring employability rather than consulting the webpages devoted to employability. As has been mentioned earlier, the deliberate attempt was made to access and explore the hidden, implicit discourse rather than that which was exhibited and explicit in a bid to seek a more authentic discourse, not necessarily the one the institution aspired to create. Secondly, the data provides a snapshot in time rather than the whole picture. As has been mentioned earlier, websites are designed to be fluid which is why we considered more than one webpage in an attempt to construct a more robust story around the discourse the internet was revealing and asked for comment from recent graduates. This has not been achieved in its entirety - ideally a greater number of HEIs ought to have been targeted, webpages considered and especially recent graduates asked for comment. Even though attempts were made to recruit recent graduates to take part in this research, the numbers that volunteered were fewer than anticipated. Therefore we acknowledge that their commentary does not provide a definitive validation of our findings, but some appreciation of whether there are similarities in the discourse coming from higher education and the experiences of students. Thirdly, the international comparison is only between two countries. As both speak the same language and share similar values and traditions, we felt they provided us with a natural comparison. However, the inclusion of a country like China or India might have added a richer dimension to the findings.

\section{Concluding remarks}

Having used the internet to conduct content text analysis, inserting our findings into a MIT SIMILE software package to visualise the data sets and seeking comments from recent graduates to verify our initial findings, it has been possible to attain an initial idea of the actual employability discourse within higher education in the UK and USA. Our findings seem to resonate with this idea that the employability discourse within higher education is dynamic and continually shifting (Boden and Nedeva 2010). There are some differences in emphasis among the two national contexts and the HEIs themselves; this is to be expected. The findings suggest that, in the UK, the broad discourse centres around government policies, which have a significant impact upon how employability discourse is presented and targeted preparation for employment, namely through career management and bolted-on activities. In the USA, findings reveal that the broad discourse is centred on the institutional vision, whereby HEIs adhere to their own institutional brand in terms of who they attract, what facilities they offer and what expertise they have, and social inclusion which incorporates policies around support for disabled and disadvantaged students. Findings from both contexts suggest a steer towards a neoliberal ideology with employability for employment being at the heart of it. Recent research reflects these findings and points to HEIs becoming more entrepreneurial and customer-focused, especially those in Anglophone countries (Kalfa \& Taksa 2015). We would argue that the employability agenda, as informed by global events 
and government ideologies, impacts upon higher education rather than higher education setting and controlling the employability agenda, and this is a key shift in determining the direction, context and content of the discourse. To follow on from this, it would be helpful to compare the discourse that has been revealed through our findings with that proposed by institutional managers and determine where the gap lies between the two. An unsuccessful attempt was made to do this, but there would be value in attaining such a perspective.

Having considered the findings and the direction of travel regarding the employability discourse, it is also worth mentioning the widening divide between employability (for employment) and curriculum (to enhance academic performance). Curriculum has always been purported as transformational, whereas the current employability discourse signifies transaction. Our findings suggest that academic learning and employability no longer complement one another and that within higher education, both in the UK and USA, the two are functionally different. The discourse around employability is broader and no longer merely about the development of soft or transferable skills that can be integrated and embedded into the curriculum (for example Drummond et al. 1998; Fallows \& Steven 2000); a narrow view brings limitations as, by focusing on transferable skills, social and cultural capital - key determinants in the development of employability - are ignored (Wilton 2011). In relation to this, it would be useful to take a closer look at the employability strategies of all the HEIs featured in this piece of research to establish how employability preparedness is expected to occur within and outside the curriculum and how closely the strategies align with, or enhance, academic learning.

As an end note we would add that previous research (Moore \& Morton 2015) and this current study concur that there is satisfaction among recent graduates both in the UK and in the USA. There is appreciation for what HEIs do for their students and the efforts that have been made in supporting graduate employability; no doubt higher education is experiencing some difficulty in pinning down exactly what is meant by the employability discourse and in determining its direction - the shifting landscape adds to the difficulty, but it has taken up this challenge with aplomb.

\section{Endnotes}

${ }^{1}$ Data visualisation tool designed and developed at Massachusetts Institute of Technology

${ }^{2}$ https://www.thecompleteuniversityguide.co.uk/league-tables/rankingshttps://www.usnews.com/best-colleges/rankings/national-universities

Authors' contributions

Both authors read and approved the final manuscript.

\section{Publisher's Note}

Springer Nature remains neutral with regard to jurisdictional claims in published maps and institutional affiliations.

Author details

${ }^{1}$ King's Learning Institute, King's College London, Stamford Street, London SE1 9NH, UK. ${ }^{2}$ Centre for Technology Enhanced Learning, King's College London, London, UK. 
Aune B. (1998). Higher education and disability in the United States of America: the context, a comprehensive model and current issues. In A. Hurst (Ed.), Higher Education and Disabilities: international approaches. Aldershot: Ashgate. Berelson B. (1952). Content analysis in communication research. Glencoe, IL: Free Press.

BIS (2012), Business-University Collaboration: Government Response to the Wilson Review, Department for Business, Innovation and Skills, London, available at: https://www.gov.uk/government/uploads/system/uploads/attachment_ data/file/32399/12-903-following-up-wilson-business-university-collaboration-next-steps.pdf. Accessed 18 May 2016.

BIS (2013), Enterprise Education: Impact in Higher and Further Education, Department for Business, Innovation and Skills, London, available at: https://www.gov.uk/government/uploads/system/uploads/attachment_data/file/208715/ bis-13-904-enterprise-education-impact-in-higher-education-and-further-education.pdf. Accessed 18 May 2016.

BIS (2014), National Strategy for Access and Student Success in Higher Education, Department for Business, Innovation and Skills, London, available at: https://www.gov.uk/government/uploads/system/uploads/attachment_data/file/ 299689/bis-14-516-national-strategy-for-access-and-student-success.pdf. Accessed 15 July 2016.

Blackmore, J. \& Sachs, J. (2003), Zealotry or nostalgic regret? Women leaders in technical and further education in Australia: agents of change, entrepreneurial educators or corporate citizens, Gender, Work and Organisation, 10, 478-503, doi:10.1111/1468-0432.00207

Blaxell, R. \& Moore, C. (2012), Connecting academic and employability skills and attributes. In Developing student skills for the next decade. Proceedings of the 21st Annual Teaching Learning Forum, 2-3 February 2012. Perth: Murdoch University. http://www.roger-atkinson.id.au/tlf2012/refereed/blaxell.pdf. Accessed 10 Mar 2014.

Boden, R. \& Epstein, D. (2006), Managing the research imagination: globalisation and research in higher education, Globalisation, Societies and Education, 4(2), 223-236, doi:10.1080/14767720600752619

Boden, R. \& Nedeva, M. (2010), Employing discourse: universities and graduate 'employability', Journal of Education Policy, 25(1), 37-54, doi:10.1080/02680930903349489

Bok D. (2006). Our Underachieving Colleges. Princeton NJ: Princeton University Press.

Bringle, R.G. \& Hatcher, J.A. (2002), Campus-Community Partnerships: the terms of engagement, Journal of Social Issues, 58(3),503-516, doi:10.1111/1540-4560.00273

Brint, S., Riddle, M. \& Hanneman, R.A. (2006), Reference sets, identities and aspirations in a complex organizational field: the case of American four-year colleges and universities, Sociology of Education, 79(3), 126-140, doi:10.1177/ 003804070607900303

Brint, S. \& Clotfelter, C.T. (2016), US higher education effectiveness, The Russell Sage Foundation Journal of the Social Sciences

Brown, P., Hesketh, A. \& Williams, S. (2003) Employability in a knowledge-driven economy, Journal of Education and Work, 16(2), 107-126, doi:10.1080/1363908032000070648

Bryman A., \& Bell E. (2007). Business Research Methods. New York: Oxford University Press.

Bylsma, P.E. (2015), The teleological effect of neoliberalism on American higher education (special section), College Student Affairs Leadership, 2(2), article 3

Confederation of Business Industry (2009), Future Fit: preparing graduates for the world of work, Available at: http:// www.universitiesuk.ac.uk/policy-and-analysis/reports/Documents/2009/future-fit-preparing-graduates-for-the-worldof-work.PDF. Accessed 27 June 2017.

Christie, F. (2017) The reporting of university league table employability rankings: a critical review, Journal of Education and Work, 30:4, 403-418, DOl: 10.1080/13639080.2016.1224821

Condon, E. \& Callahan, M. (2008), Individualised career planning for students with significant support needs utilising the discovery and vocational profile process, cross-agency collaborative funding and social security work incentives, Journal of Vocational Rehabilitation, 28(2), 85-96, jvr00407

Cranmer, S. (2006), Enhancing graduate employability: best intentions and mixed outcomes, Studies in Higher Education, 31(2), 169-184, doi:10.1080/03075070600572041

Crossman, J.E. \& Clarke, M. (2010), International experience and graduate employability: stakeholder perceptions on the connection, Higher Education, 59, 599-613, doi:10.1007/510734-009-9268-z

Dearing R. (1997). National Committee of Inquiry into Higher Education (Dearing committee), Higher Education in the Learning Society, Report of the National Committee of Inquiry into Higher Education. London: The Stationary Office.

Drummond I., Nixon I., \& Wiltshire J. (1998). Personal transferable skills in higher education: the problems of implementing good practice. Quality Assurance in Education, 6(1), 19-24.

Eckel, P.D. \& King, J.E., (2004), An Overview of Higher Education in the USA

Eyring H., \& C. Christensen. (2013). "Changing the DNA of Higher Education." American Council on Education. https:// www.acenet.edu/newsroom/Documents/Changing-the-DNA-of-Higher-Ed.

Fallows S., \& Steven C. (2000). Integrating Key Skills in Higher Education. London: Kogan Page.

Farenga S. A., \& Quinlan K. M. (2016). Classifying university employability statistics: three case studies and implications for practice and research. Journal of Education and Work, 29(7), 767-787.

Frankham, J. (2016), Employability and higher education: the follies of the 'productivity challenge' in the Teaching Excellence Framework, Journal of Education Policy, 29(7), 767-787, doi:10.1080/13639080.2015.1064517

Hahn, H., (1988), The politics of physical differences: disability and discrimination, Journal of Social Issues, 44(1), 39-47, doi:10.1111/j.1540-4560.1988.tb02047.x

Harvey, L. \& Bowers-Brown, T. (2004), Are there too many graduates in the UK? A literature review and an analysis of graduate employability, Industry and Higher Education, 18(4), 243-254, doi:10.5367/00000000041667538

Hazelkorn, E. (2007), The impact of league tables and ranking systems on higher education decision making, Higher Education Management and Policy, 19(2), 1-24, doi:10.1787/hemp-v19-art12-en

Henry, C. (2013), Entrepreneurship education in higher education: are policy makers expecting too much? Education + Training, 55(8/9), 836-848, doi:10.1108/ET-06-2013-0079

High Fliers (2010), The UK Graduate Careers Survey 2010, High Fliers Research Ltd: London, available at http://www. highfliers.co.ukJ. Accessed 28 Jan 2014.

Higson, H. (2012), How to Improve Employability: Aston University's Placements Programme. The Guardian Higher Education Network, https://www.theguardian.com/higher-education-network/blog/2012/feb/29/aston-university-studentplacements. Accessed 15 Feb 2017. 
Hillage, J. \& Pollard, E. (1998) Employability: developing a framework for policy analysis, DfEE Research Briefing No. 85. London, DfEE. Hinchliffe, G.W. \& Jolly, A. (2011), Graduate identity and employability, British Educational Research Journal, 37(4), 563-584, doi:10.1080/01411926.2010.482200

Hoang, T.V.Y. \& Rojas-Lizana, I. (2015), Promotional discourse in the websites of 2 Australian universities: a discourse analytic approach, Cogent Education, 2(1), doi:10.1080/2331186X.2015.1011488

Helyer, R \& Lee, D. (2014), The role of work experience in the future employability of higher education graduates, Higher Education Quarterly, 68(3), 348-372, doi:10.1111/hequ.12055

Holmes, L (2001), Competing perspectives on graduate employability: possession, position or process? Studies in Higher Education, 38(4), 538-554, doi:10.1080/03075079.2011.587140

Hsieh, H-F, and Shannon, S.E. (2005), Three approaches to qualitative content analysis, Qualitative Health Research, 15(9), 1277-1288, DOI: 10.1177/1049732305276687

Jackson, N. (2011), Recognising a more complete education through a Lifeworld Learning Award, Higher Education, Skills and Work-based Learning, 1(3), 247-261, doi:10.1108/20423891111179641

Jarrow, J. (1993), Beyond ramps: new ways of viewing access, New Directions for Student Services, 64, 5-16, doi:10. $1002 / s s .37119936403$

Kalfa, S. \& Taksa, L. (2015), Cultural capital in business higher education: reconsidering the graduate attributes movement and the focus on employability, Studies in Higher Education, 40(4), 580-595, doi: 10.1080/0375079.2013. 842210

Kena G., Musu-Gillette L., Robinson J., Wang X., Rathbun A., Zhang J., Wilkinson-Flicker S., Barmer A., \& Dunlop Valez E. (2015). The Condition of Education. In NCES 2015-144. Washington: US department of Education https://nces.ed. gov/pubs2015/2015144.pdf.

Kim, I. and Kuljis, J. (2010), Applying content analysis to web-based content, Journal of Computing and Information Technology, 18(4): 369-375, doi:10.2498/cit.1001924

Kinash, S, Crane, L, Judd, M-M. \& Knight, C. (2016), Discrepant stakeholder perspectives on graduate employability strategies, Higher Education Research and Development, 35(5), 951-967, doi:10.1080/07294360.2016.1139555

Knight, P.T. \& Yorke, M. (2002) Employability through the curriculum, Tertiary Education and Management, 8, 261-276, doi:10.1023/A:1021222629067

Millican, J. (2014), Higher education and student engagement: implications for a new economic era, Education + Training, 56(7), 635-649, doi:10.1108/ET-07-2014-0077

Moore, T. \& Morton, J. (2015), The myth of job readiness? Written communication, employability and the 'skills gap' in higher education, Studies in Higher Education, doi:10.1080/03075079.2015.1067602

Morris, C. (2015), A reflection on the opportunities and challenges associated with teaching the sociology of employability, Compass: Journal of Learning and Teaching, 7(11), doi:10.21100/compass.V7i11.2016

Muetzelfeldt R., \& Massheder J. (2003). The SIMILE visual modelling environment. European Journal of Agronomy, 18, 345-358.

National Student Forum (2009), Annual Report, available at nationalstudentforum.com/report/ideas/employability. Accessed 15 Jan 2014.

Oliver, B. (2015), Redefining graduate employability and work-integrated learning: proposals for effective higher education in disrupted economies, Teaching and Learning for Graduate Employability 6 (1), 56-65, doi:10.21153/ jtlge2015vol6no1art573

Pasque P. A., Smerek R. E., Dwyer B., Bowman N., \& Mallory B. L. (2005). Higher education collaboratives for community engagement and improvement. National Forum on Higher Education for the Public Good.

Rae D. (2007), Connecting enterprise and graduate employability, Education + Training, 49(8/9), 605-619, doi:10.1108/ 00400910710834049

Roberts G. (2002). SET for Success: the Report of Sir Gareth Roberts' Review, The supply of people with science, technology, engineering and mathematical skills. London: HM Treasury.

Robst J. (2007), Education and job match: the relatedness of college major and work, Economics of Education Review, 26(4), 397-407, doi:10.1016/j.econedurev.2006.08.003

Rosenberg, S., Heimler, R. \& Morote, E-S. (2012), Basic employability skills: a triangular design approach, Education + Training, 54(1), 7-20, doi:10.1108/00400911211198869

Rourke L., Anderson T., Garrison R. D., \& Archer W. (2001). Methodological Issues in the Content Analysis of Computer Conference Transcripts. International Journal of Artificial Intelligence in Education (IJAIED), 12, 8-22 $<$ hal-00197319>.

Ryan S., Scott B., Freeman H., \& Patel D. The Virtual University: the internet and resource-based learning (2000). London: Kogan Page.

Salmi J. and Saroyan A. (2007), League tables as policy instruments, Higher Education Management and Policy, 19(2), 1-38, doi:10.1787/hemp-v19-art10-en

Shore C., \& Wright S. (2000). Coercive accountability: the rise of audit culture in higher education. In M. Strathern (Ed.), Audit Cultures: anthropological studies in accountability, ethics and the academy (pp. 57-89). London/New York: Routledge.

Social Mobility and Child Poverty Commission (2015), State of the Nation: social mobility and child poverty in Great Britain, Crown copyright, ISBN: 9781474125635

Speight S., Lackovic N. \& Cooker L. (2013), The contested curriculum: academic learning and employability in higher education, Tertiary Education and Management, 19(2), 112-126, doi:10.1080/135838883.2012.756058

Teichler U. (2009). Higher education and the World of Work: conceptual frameworks, comparative perspectives, empirical findings. Sense Publishers: Rotterdam and Taipei.

Teichler, U. (2015), Changing perspectives: the professional relevance of higher education on the way towards the highly-educated society, European Journal of Education, 50(4), 461-477, doi:10.1111/ejed.12146

The Chronicle of Higher Education and American Public Media's Marketplace (2012), The role of Higher Education in Career Development: employer perceptions, Maguire Associates Inc.

Tholen, G. (2015), What can research into graduate employability tell us about agency and structure? British Journal of Sociology of Education, 36(5), 766-784, doi:10.1080/0142692.2013.847782 
Tomlinson, M. (2008), The degree is not enough: students' perceptions of the role of higher education credentials for graduate work and employability, British Journal of Sociology of Education, 29(1), 49-61, doi:10.1080/ 01425690701737457

Tomlinson, M. (2016), Student perceptions of themselves as 'consumers' of higher education, British Journal of Sociology of Education, doi:10.1080/01425692.2015.1113856

Trow M. (2007). Reflections on the transition from elite to mass to universal access: forms and phases of higher education in modern societies since WWII. In J. J. F. Forrest, \& P. Altbach, International Handbook of Higher Education (Eds.). Dordrecht: Springer.

UK Commission for Employment and Skills (2014), Understanding Skills and Performance Challenges in the Logistics Sector, UKCES, https://www.gov.uk/government/organisations/uk-commission-for-employment-and-skills

Valenzuela F. (2013). On employability in higher education and its relation to quality assurance: between disidentification and dethroning. Ephemera: Theory and Politics in Organization, 13(4), 861-873 ISSN 1471-2866.

Voinov, A., Kolagani, N., McCall, M.K., Glynn, P.D., Kragt, M.E., Ostermann, F.O., Pierce, S.A. \& Ramu, P. (2016), Modelling with stakeholders - next generation, Environmental Modelling and Software, 77, 196-220, doi:10.1016/j.envsoft.2015.11.016

Weber R. P. (1990). Basic content analysis. Beverly Hills: Sage.

Wilton N. (2011). The shifting sands of employability. CESR Review, 4, 2-5 Available from: http://eprints.uwe.ac.uk/14530/.

Yorke, M. (2006), Employability in higher education: what it is - what it is not. Retrieved $5^{\text {th }}$ December 2016 from https://www.heacademy.ac.uk/system/files/id116_employability_in_higher_education_336.pdf.

Yorke M. (2007). Employability in higher education. In E. Fromment, J. Kohler, L. Purser, \& L. Wilson (Eds.), EUA Bologna Handbook: making Bologna work (vol. part 1, pp. 4-1). Berlin: Raabe.

Submit your manuscript to a SpringerOpen ${ }^{\circ}$ journal and benefit from:

- Convenient online submission

- Rigorous peer review

- Open access: articles freely available online

- High visibility within the field

Retaining the copyright to your article

Submit your next manuscript at $>$ springeropen.com 